\title{
Microbial and Biochemical Aspects of Antibiotic Producing Microorganisms from Soil Samples of Certain Industrial Area of India- An Overview
}

\author{
Atul Pratap Singh ${ }^{1}$, R.B. Singh ${ }^{2}$ and Sanjay Mishra, ${ }^{1, *}$ \\ ${ }^{1}$ School of Biotechnology, IFTM University, Lodhipur Rajput, Delhi Road (NH-24), Moradabad 244001, U.P., India \\ ${ }^{2}$ Halberg Hospital \& Research Center, Civil Lines, Moradabad 244 001, U.P., India
}

\begin{abstract}
Antimicrobial agents produced by the soil borne microorganisms like (Actinomycetales, Pseudomonas auregenosa, staphyllo coccous spp etc) community in the industrial areas as well as in agricultural soil have been reported to amend with diverse amounts of municipal solid waste compost (MSWC) or farmyard manure (FM). It was shown, by using the 16S rDNA polymerase chain reaction-restriction fragment length polymorphism and sequencing methods for Actinomycetales isolates, tow major clusters. The cluster SI is composed of two related families: Streptomycetaceae, dominant family and Pseudonocardiaceae. However, SII is composed of Nocardioidaceae family. The actinomycetes yielded about $70 \%$ of these, and the remaining $30 \%$ are products of filamentous fungi and non-actinomycete bacteria. Most of the bioactive compounds from actinomycete sort into several major structural classes such as amino glycosides (e.g., streptomycin and kanamycin), ansamycins (e.g., rifampin), anthracyclines (e.g., doxorubicin), $\beta$-lactam (cephalosporins), macrolides (e.g., erythromycin), and tetracycline. The present paper is the compilation of studies aimed at isolating and characterizing the nutraceutically as well as medicinally significant compounds, mainly antibiotics from the soil of vicinity of certain industrial areas of India, capable of acting on clinically resistant strains of infectious organisms.
\end{abstract}

Keywords: Actinomycetes, Amino glycosides, Antimicrobial agents, $\beta$-lactam, Cephalosporins, Erythromycin.

\section{INTRODUCTION}

Soil as a living system inhabits assorted cluster of living organisms, both micro flora (fungi, bacteria, algae and actinomycetes) and micro-fauna (protozoa, nematodes, earthworms, moles, ants). The density of living organisms in soil is exceptionally high i.e. as much as billions / gm of soil, usually density of organisms is less in cultivated soil than uncultivated / virgin land and population decreases with soil acidity [1]. While exploring the studies on microbial isolation in view of screening nutraceutically significant, the activities of metal ions and metalloids are also taken into consideration. The logical reason behind it is that metal ions such as iron and copper are among the key nutrients that must be provided by dietary sources. In developing countries, there is an enormous contribution of human activities to the release of toxic chemicals, metals and metalloids into the atmosphere [2]. These toxic metals are accumulated in the dietary articles of man. Numerous foodstuffs have been evaluated for their contributions to the recommended daily allowance both to guide for satisfactory intake and also to prevent over exposure. Further, food chain polluted with toxic metals and metalloids is an important route of human exposure and may cause several dangerous effects on human [2]. Autotrophs use inorganic carbon

*Address correspondence to this author at the School of Biotechnology, IFTM University, Lodhipur Rajput, Delhi Road (NH-24), Moradabad 244 001, U.P., India; Tel: +91-591-2360817; Fax: +91-591-2360818;

E-mails: sanjaymishra@iftmuniversity.ac.in, sanjaymishra66@gmail.com from $\mathrm{CO} 2$ and are "primary producers" of organic matter, whereas heterotrophs employ organic carbon and are decomposers/consumers [2]. Organic compounds include cellulose, lignins and proteins (in cell wall of plants), glycogen (animal tissues), proteins and fats (plants, animals). Cellulose is degraded by certain specific [3]. Antibiotics are one of the most significant commercially exploited secondary metabolites produced by the bacteria and employed in a wide range. Most of the antibiotic producers used today are the soil microbes. Fungal strains and Streptomyces members are extensively used in industrial antibiotic production [4]. Bacterium is easy to isolate, culture, maintain and to improve their strains. Microbes are omni present and exist in a competitive environment. Bacillus species being the predominant soil bacteria because of their resistant endospore formation and production of vital antibiotics like bacitracin etc. are always found inhibiting the growth of the other organisms [3]. An enhancement in the antibiotic production has been studied under various parameters like temperature, $\mathrm{pH}$, carbon source concentration, and Sodium nitrate concentration, which may help in the industrial production. The extracted substance was found effective against the gram positive endospore forming bacilli and gram positive cocci. Though a large number of antibiotics are commercially available [5], the search for the most potential one is still on, and the present compiled work may provide some potential information on the antibiotic production and the control of microbial strains.

A preliminary investigation was performed about the presence of industrially important thermophilic bacteria in 
the hot springs and in its vicinity to the site of industrial area reflecting the bioactive status of the two randomly picked up clones of bacterium samples [5, 6]. The staining, morphological, biochemical, growth parameters, antibiotic studies proved that the bacteria are of gram negative and rod shaped nearer to the Escherichia coli cell type. Antibiotics are the best known products of actinomycete. Over 5,000 antibiotics have been identified from the cultures of Grampositive and Gram-negative organisms, and filamentous fungi, but only about 100 antibiotics have been commercially used to treat human, animal and plant diseases [6]. Known so far, the actinomycetes produce an enormous variety of bioactive molecules, e.g., antimicrobial compounds [7]. One of the first antibiotics used is streptomycin produced by Streptomycin grisius [8]. On the whole, the last 55 years have seen the discovery of more than 12,000 antibiotics. The actinomycetes yielded about $70 \%$ of these, and the remaining $30 \%$ are products of filamentous fungi and nonactinomycete bacteria [9]. Most of the bioactive compounds from actinomycete sort into several major structural classes such as amino glycosides (e.g., streptomycin and kanamycin) [10], ansamycins (e.g., rifampin) [11], anthracyclines (e.g., doxorubicin) [12], $\beta$-lactam (cephalosporins) [13], macrolides (e.g., erythromycin) [14] and tetracycline [15]. In the past decade, pharmaceutical as well as nutraceutically important antibiotics were recognized as emerging soil pollutants. Compounds such as tetracyclines and sulfonamides reach agricultural land mostly through contaminated manure from medicated livestock used as fertilizer [16, 17]. Pharmaceutical antibiotics are a large group of structurally diverse compound classes that comprise mostly polar and ionizable compounds [18]. Hence, their soil sorption behavior deviates from that of well-studied hydrophobic organic pollutants. In addition to hydrophobic interactions, antibiotics may sorb to soils via hydrogen bonding, van der Waals forces, cation exchange, cation bridging, and surface complexes [19, 20]. The present scientific essay is the compilation of studies aimed at isolation and characterization of the antibiotics from the soil of vicinity of certain industrial areas of India under following sections:

\section{Industrialization, Biostimulation and Bioaugmentation}

As industrialization expands, petroleum hydrocarbons become a greater potential source of contaminants in the soil and water environments [1-3]. Recently, more and more oil spill accidents have been reported. Chang and Lin [2] reviewed 242 accidents with storage tanks in industrial facilities over the last 40 years. They reported that $74 \%$ of accidents occurred in petroleum refineries, oil terminals, or storage facilities and other industries [21]. To remediate oil terminals contaminants in these environments, biostimulation and bioaugmentation are generally considered as ecofriendly techniques. However, the use of extrinsic microorganisms is unlikely to be globally acceptable. Further, biostimulation is a technique that relies on increasing the activity of the resident bacteria by adding up the factors that are shown to exhibit the limitation of activity, such as nutrients or air. This technique is projected to be rather more effective because the indigenous bacteria are likely to be better adapted to the soil environment requiring treatment [2]. However, biostimulation sometimes does not work well and may take longer because bacteria with the ability to degrade xenobiotics may be scarce at contaminated sites or because the high-concentration of antibiotics reduces the activity of degrading microorganisms.

\section{Assimilation of Phosphates by Microorganisms}

Phosphorous is essential for growth and productivity of plants. It plays a pivotal role in plants in certain specific physiological and biochemical activities such as cell division, photosynthesis, and development of good root system and proper utilization of carbohydrates [22]. Phosphorous deficiency leads to the leaves turning brown accompanied by small leaves, weak stem and slow development. In ancient times the use of animal manures to provide phosphorous for plant growth was common agricultural practice. Organically bound phosphorous enters in soil during the decay of natural vegetation, dead animals and from animal excretions. At that time role of micro flora on soil fertility was hardly understood. Assimilation of phosphate from organic compounds by plants and microorganisms take place through the enzyme, phosphatase that is present in a wide variety of soil microorganisms. The medium [23] used to monitor the population density of phosphate solubilizers exhibit a clear zone around the colonies reflecting the well demarcated phosphate solubilization. Phosphate cleaved as a consequence of the specific action of the enzyme phosphatase secreated by phosphate solubilising bacteria was performed according to the protocol described by Alanis [24].

\section{Antimicrobial Agents}

Antimicrobial agents are natural or synthetic chemical substances which have the capacity of inhibiting or terminating total metabolic cell activity. These chemical molecules are classified depending on their targets. They can also be referred to as broad or narrow spectrum depending on its strength of action towards their targets, principally including (a) cell wall synthesis; (b) protein synthesis and (c) DNA replication. The major classes of antimicrobial agents are as (a) lactams including penicillins, cephalosporins, monobactams, carbapenems; (b) aminoglycosides; (c) tetracyclines; (d) sulfonamides; (e) macrolides such as erythromycin; (f) quinines; and (g) glycopeptides such as vancomycin. These secondary metabolites can affect many metabolic reactions in a cell in order to render effect. Penicillins and cephalosporins mode of action is the biosynthesis of the peptidoglycan present in the bacterial cell wall [25]. They affect specifically the transpeptidase that forms the peptide cross-linking. Beta-lactams also affect peptidoglycan synthesis by forming covalent bonds with a specific group of proteins known as the penicillin binding proteins [26]. Both gram positive and gram negative microorganisms posses these proteins and other antimicrobials such as the quinolones and noviobiocin inhibit DNA replication by affecting enzymes, namely, DNA gyrase and the eukaryotic topoisomerase II [27]. Antimicrobials, known as 6-Aniniluracil, inhibits DNA polymerase III. Classes of antimicrobials like tetracyclines, chloramphenicol and macrolides inhibit protein synthesis [28-31].

\section{Ecological Interactions}

In nature, multiple ecological interactions take place; which can be negative or positive for the organisms 
involved. The organisms and the physical-chemical conditions present in an ecological niche will delimit the type of interactions that can be observed. Competition is an interaction encountered in all habitats since the prevailing organisms need to do so in order to survive. Also, it is known that when various communities in an ecological niche utilize the same type of substrates they must compete [31]. Both theoretical and empirical studies suggest that in plant and animal communities, spirited interaction is the key determinant of species abundance and diversity [32]. As part of physiological and metabolic processes, communitiest, which are found colonizing definite areas provide the production of intracellular or extra-cellular low molecular weight components such as alcohols, fatty acids, secondary metabolites and some antimicrobial agents [32-34]. The substances secreted to the environment can be harmful or toxic to the surrounding organisms acting as a competitive advantage for the secretor. Amensalism or antagonism is the term used in the classification of ecological interactions where one component has the competitive advantage of producing and secreting substances that have inhibitory effects on other populations [35, 36]. The substances must alter the habitat in a disadvantageous style so that the interaction may be categorized as antagonism or amensalism.

\section{Soil Microbial Interactions}

An ecological niche is composed of many microhabitats; each microhabitat is composed of a microscopic diversity which includes bacteria, protozoa, fungi, and a macroscopic diversity that includes plants and insects. Soil is a complex medium in which one can encounter many kinds of microbial communities. Application of nucleic acid-based techniques to analyze soil microbial communities has revealed high prokaryote diversity [37]. The microbial diversity or communities present in soil principally depend on the composition of the soil and many physical chemical properties that the medium possesses. Also, the flora and decomposing organic mater on the surface of the soil will influence vastly with the microbial diversity present. For example, the fallen trees, barks and flowers provide nutrients both to the microbes and plants present, through microbial degradation of carbohydrates, lipids and proteins to sugars, fatty acids, glycerol and amino acids and respectively to mineralization. Besides providing these nutrients, plant secondary metabolites that are generally toxic to microorganisms will need to be degraded or detoxified by certain microbes. These degraders (microbes) are selectively pressured and ultimately evolve to produce novel secondary metabolites possibly to counteract the toxic plant secondary metabolites [38]. There are approximately $10^{6}-10^{9}$ colony forming unites per gram of soil. Microbes present in medium posses advantages that will permit or facilitate their survival in that medium. For example, Skujins research has demonstrated that in desert crusts or in soil that has low water availability, gram-positive and spore forming microbes are most abundant. The gram-positive bacteria posses a thicker layer of murein in their cell wall which makes the cell less vulnerable to the limiting conditions present in these habitats. Also, spore forming bacteria can resist long periods of desiccation and limiting nutrient conditions since they compact and protect their genomic material in the bacterial spore, until conditions are favorable for sporulation to occur [38].

\section{The Soil Rhizosphere}

Interactions that take place in the rhizosphere can be beneficial for the plant and also for the microbial community present. The effect that takes place in the soil rhizosphere is due to the influx of mineral nutrients to the plants roots through diffusion alongside the efflux and accumulation of plant root exudates [37, 38]. Every metabolically active system has the capability of secreting molecules as byproducts. Exudates released by plants have various effects in the surrounding ecosystem. For example, they can alter the physical-chemical properties of soil by inhibiting the growth of other plants, enhancing symbiotic relationships, and selecting the type of microbiota that can colonize the area. Plant exudates can attract plant pathogens such as nematodes $[37,38]$.

\section{Soil Antimicrobial Agent Producing Microbes}

Many groups of microorganisms like gram-positive, gram-negative bacteria and fungi have the ability of synthesizing antimicrobial agents. Pandey et al. [39] state that the top cultivable antimicrobial agent producers present in soils are the actinomycetes. The actinomycetes are a group of gram-positive bacteria that exhibit characteristics of both bacteria and fungi. These microbes produce filamentous structures which agglomerate forming pseudo-mycelia. Actinomycetes are also spore forming microbes, characteristic shared with fungi. Some of the characteristics that they share with bacteria is the formation and composition of the cell wall, the flagella and the ribosome. About $10 \%-33 \%$ of the total bacterial community present in soil is comprised by these bacteria, being the genera Streptomyces and Nocardia the most abundant actinomycetes found in soil. The genus Streptomyces is the responsible of the synthesis of the majority of antimicrobial agents with clinical importance amphotericin, erythromycin, streptomycin, tetracycline, and rifamycin. Protein synthesis is the mode of action of all the above except for amphotericin which attacks the cell membrane. Also the majority of these antibiotics are of broad spectrum. These microbes exhibit a vast metabolic versatility. They can complete many physiological cycles that produce intermediate molecules such as enzymes or secondary metabolites with antibacterial, antifungal and antiviral capabilities [40]. Another group of gram-positive bacteria present in soil and responsible for the production of antimicrobial agents with clinical and agricultural importance is the genus Bacillus. This genera is characterized by being gram-positive, spore forming rods [41]. It has been demonstrated that these microbes produce antimicrobial agents in various stages of their growth curve. For example, $B$. subtilis can produce non ribosomal oligopeptides with antifungal and antimicrobial properties such as surfactins, inturinics and bacilysin. Ribosomal antibiotics are also synthesized by this strain which include subalancin and subtilosin [41]. Cyanobacteria are known to be colonized by various heterotrophic bacteria. With a view to understand the associated organisms from cyanobacterial products especially 6 different Spirulina products such as two forms of Spirulina powder, one crunchy form and three different 
tablets were selected. A total of 30 bacterial strains were isolated and their biochemical and cultural characteristics were studied. The isolates were subjected for silver nanoparticle production. Microscopic results revealed that most of them were gram positive and non-motile. Among the 30 isolates most of them can able to synthesize nanoparticles with silver. It indicates that the colonial characteristics alone cannot serve as a tool to characterize the bacterial isolates. Hence these isolates were carefully examined and selected for further analysis [41].

Actinomycetes are the most widely distributed group of microorganisms in nature which primarily inhabit the soil [39]. They have provided many important bioactive compounds of high commercial value and continue to be routinely screened for new bioactive compounds. These searches have been remarkably successful and approximately two thirds of naturally occurring antibiotics, including many of medical importance, have been isolated from actinomycetes [40]. Almost $80 \%$ of the world's antibiotics are known to come from actinomycetes, mostly from the genera Streptomyces and Micromonospora [41, 42]. According to the World Health Organization, over-prescription and the improper use of antibiotics has led to the generation of antibiotic resistance in many bacterial pathogens. Nowadays, the drug resistant strains of pathogen emerge more quickly than the rate of discovery of new drugs and antibiotics. Because of this, many scientists and pharmaceutical industry have actively involved in isolation and screening of actinomycetes from different untouched habitats, for their production of antibiotics [39-41]. Serious infections caused by bacteria have become resistant to commonly used antibiotics and become a major global healthcare problem in the 21 st century [40]. Staphylococcus aureus, for instance, a virulent pathogen that is responsible for a wide range of infections, has developed resistance to most classes of antibiotics [38, 39]. Clinicians and public health officials have faced hospital acquired drug resistant $S$. aureus, which also bears resistance to many antibiotics. Hence there is need to rediscover new drugs active against these drug resistance pathogens. Majority of the actinomycetes in soil that are potential drug sources remain uncultivable, and therefore inaccessible for novel antibiotic discovery. Enright [28] reviewed the literature on isolation of actinomycetes and suggested that only $10 \%$ of the actinomycetes are isolated from nature. Most of the antibiotics in use today are derivatives of natural products of actinomycetes and fungi $[29,30]$. Actinomycetes can be isolated from soil and marine sediments. Although soils have been screened by the pharmaceutical industry for about 50 years, only a small fraction of the surface of the globe has been sampled, and only a small fraction of Actinomycetes taxa has been discovered. This study was undertaken to isolate Actinomycetes from the soil samples of wasteland and garden of Ghaziabad, India and to assess their anti-bacterial properties. The resistance problem demands that to discover new antibacterial agents effective against pathogenic bacteria resistant to current antibiotics. So we need to screen more and more actinomycetes from different habitats for antimicrobial activity in hope of getting some actinomycetes strains that produce antibiotics that have not been discovered yet and active against drug resistant pathogens.
A total of 117 actinomycetes strains were isolated from the wasteland alkaline and garden soil samples of the Ghaziabad and screened for their anti-bacterial activity. They were evaluated for their inhibitory activities on four test microorganisms. Fifteen actinomycetes isolate which exhibited antimicrobial activity against at least two of the test organisms and were characterized by conventional methods [42-44]. The cultural characteristics of isolates were also studies in different culture media [41]. The results indicated that six isolates were highly active against Staphylococcus aureus strains. Seven isolates were highly active with an inhibition zone more than $20 \mathrm{~mm}$ in diameter. Most of the isolates inhibited growth of the Gram negative bacteria tested. All the antibiotic producing actinomycetes were isolated at different temperatures from non agricultural wasteland alkaline soil and compost rich garden soil. Fifteen isolates showed activity against bacteria in which most of them from wasteland alkaline soil where the less interference by human for agriculture or other purpose. These microorganisms may have capability to produce some of the most important antibiotics ever developed [32, 45-52] provided a bioremediation concept [53] is taken into consideration prior to isolation and purification of antibiotics. Further, the sorption of sulfonamides is strongly influenced by $\mathrm{pH}$ and ionic strength [54-56]. Relevant sorption occurs to both soil organic matter (SOM) and soil minerals, that is, clay minerals and pedogenic oxides [55, 57]. However, as for other compounds sorption is dominated by SOM, and first studies were published that further elucidated the relevant sorption sites and mechanisms [57-59]. It was reported that sulfonamide antibiotics exhibit strong nonlinear sorption to functional groups of SOM through preferred site-specific sorption via hydrogen bonds and van der Waals interactions. In part strong desorption hysteresis and rapid formation of non-extractable residues were reported $[59,60]$ that indicates reaching of an energetically favorable status and inclusion of sulfonamides in voids of soil sorbents. Correlation with the abundance of SOM structural features was used to assign preferred binding sites of sulfonamides to SOM [57-59].

\section{CONFLICT OF INTERESTS}

Declared none.

\section{ACKNOWLEDGEMENTS}

The present paper is concerning with a piece of Ph.D. program of the author APS registered at IFTM University, Moradabad, U.P., India. The authors are grateful to Prof. (Dr.) Rajiv Dutta and Prof. (Dr.) S.K. Maheshwari for timeto-time suggestions and inspiration enabling them to successfully accomplish the write-up of this manuscript. At last but not the least, the assistance from the end of Mr. S.P. Dwivedi and Abhishek Tyagi is also duly acknowledged.

\section{REFERENCES}

[1] Mishra S, Dwivedi SP, Singh RB. A review on epigenetic effect of heavy metal carcinogens on human health. Open Nutr J 2010; 3: 188-93.

[2] Mudgal V, Madaan N, Mudgal A, Singh RB, Mishra S. Effect of toxic metals on human health. Open Nutr J 2010; 3: 94-9.

[3] Gravrilescu M. Overview of in situ remediation technologies for sites and ground water. Environ Eng Manage J 2006; 3: 45-70. 
[4] Labeda DP. Multilocus sequence analysis of phytopathogenic species of the genus Streptomyces. Int J Sys Evol Microbiol 2010; 61(10): 2525.

[5] Mathew AG, Cissell R, Liamthong S. Antibiotic resistance in bacteria associated with food animals: a United States perspective of livestock production. Foodborne Pathog Dis 2007; 4(2): 115-33.

[6] Dedysh SN, Pankratov TA, Belova SE, Kulichevskaya IS, Liesack W. Phylogenetic analysis and in situ Identification of Bacteria community composition in an acidic Sphagnum Peat Bog. Appl Environ Microbiol 2006; 72(3): 2110-7.

[7] Sen SK, Mohapatra SK, Satpathy S, Gopala Rao TV. Characterization of hot water spring source isolated clones of bacteria and their industrial applicability. Int J Chem Res 2010; 2(1): 1-7.

[8] Khanna M, Solanki R, Lal R. Selective isolation of rare Actinomycestes producing novel antimicrobial compounds. Int $\mathbf{J}$ Adv Biotechnol Res 2011; 2(3): 357-75.

[9] Zhu M, Burman WJ, Jaresko GS, et al. Population pharmacokinetics of intravenous and intramuscular Streptomycin in patients with tuberculosis. Pharmacotherapy 2001; 21(9): 1-4.

[10] Nanjawade BK, Chandrashekhara S, Ali MS, Prakash SG, Fakirappa VM. Isolation and morphological characterization of antibiotic producing Actinomycestes. Trop J Pharm Res 2010; 9(3): 231-6.

[11] Floss HG, Yu T. Lessons from the rifamycin biosynthetic gene cluster. Curr Opin Chem Biol 1999; 3(5): 592.

[12] Kremer LC, van Dalen E, Offringa M, et al. Anthracyclineinduced clinical heart failure in a cohort of 607 children: long-term follow-up study. J Clin Oncol 2001; 19(1): 191-6.

[13] Kollef MH. New antimicrobial agents for methicillin-resistant Staphylococcus aureus. Crit Care Resusc 2009; 11(4): 282-6.

[14] Mims C, Dockrell HM, Goering RV, et al. Attacking the Enemy: Antimicrobial Agents and Chemotherapy: Macrolides. In: Chapter 33: Medical Microbiology. 3rd ed. London: Mosby Ltd 2004; pp. 489.

[15] Harvery RA, Champe, PC. In: Lippincott's Illustrated Reviews: Pharmacology. 4th ed. Philadelphia: Lippincott, Williams and Wilkins 2009.

[16] Boxall ABA, Fogg LA, Blackwell PA, et al. Veterinary medicines in the environment. Rev Environ Contam Toxicol 2004; 180: $1-91$.

[17] Kumar K, Gupta SC, Chander Y, Singh AK. Antibiotic use in agriculture and its impact on the terrestrial environment. Adv Agron 2005; 87: 1-54.

[18] Thiele-Bruhn S. Pharmaceutical antibiotic compounds in soils-a review. J Plant Nutr Soil Sci 2003; 166: 145-67.

[19] MacKay AA, Canterbury B. Oxytetracycline sorption to organic matter by metal-bridging. J Environ Qual 2005; 34: 1964-71.

[20] Lertpaitoonpan W, Ong SK, Moorman TB. Effect of organic carbon and $\mathrm{pH}$ on soil sorption of sulfamethazine. Chemosphere 2009; 76: 558-64.

[21] Chang JI, Lin C-C. A study of storage tank accidents. J Loss Prev Process Ind 2006; 19(1): 51-9.

[22] Sharma S, Kumar V, Tripathi RB. Isolation of phosphate solubilizing microorganism (PSMs) from soil. J Microbiol Biotech Res 2011; 1(2): 90-5.

[23] Margesin R, Schinne F. Bioremediation (Natural attenuation and biostimulation) of diesel-oil-contaminated soil in an Alpine glacier skiing area. Appl Environ Microbiol 2001; 67(7):3127.

[24] Alanis AJ. Resistance to antibiotics: are we in the post-antibiotic era? Arch Med Res 2005; 36: 697-705.

[25] Drews J. Drug discovery: A historical perspective. Science 2000; 287(5460): 1960-4.

[26] Sainsbury S, Bird L, Rao V, et al. Crystal structures of Penicillinbinding protein 3 from Pseudomonas aeruginosa: Comparison of native and antibiotic-bound forms. J Mol Biol 2011; 405: 173-84.

[27] Han S, Zaniewski RP, Marr ES, et al. Structural basis for effectiveness of siderophore-conjugated monocarbams against clinically relevant strains of Pseudomonas aeruginosa. PNAS 2010; 107: 22002-7.

[28] Enright MC. The evolution of a resistant pathogen-the case of MRSA. Curr Opin Pharmacol 2003; 3: 474-9.

[29] Butler MS, Buss AD. Natural products--the future scaffolds for novel antibiotics? Biochem Pharmacol 2005; 71: 919-29.

[30] Baltz RH. Molecular engineering approaches to peptide, polyketide and other antibiotics. Nature Biotechnol 2006; 24:1533-40.
[31] Newman DJ, Cragg GM. Natural products as sources of new drugs over the last 25 years. J Nat Prod 2007; 70: 461-77.

[32] Kumar N, Singh RK, Mishra SK, Singh AK, Pachouri UC. Isolation and screening of soil Actinomycetes as source of antibiotics active against bacteria. Int J Microbiol Res 2010; 2(2): 12-6.

[33] Saadoun I, Gharaibeh R. The Streptomyces flora of Badia region of Jordan and its potential as a source of antibiotics active against antibiotic-resistant bacteria. J Arid Environ 2003; 53: 365-71.

[34] Lemriss S, Laurent F, Couble A, et al. Screening of nonpolyenic antifungal metabolites produced by clinical isolates of actinomycetes. Can J Microbiol 2003; 49: 669-74.

[35] Brun YV, Skimkets LJ. Isolation and morphological characterization of antibiotic producing actinomycetes. In: Brun YV, Skimkets LJ, Eds. Prokaryotic development. Washington DC: ASM Press 2000; pp. 11-31.

[36] Duraipandiyan V, Sasi AH, Islam VIH, et al. Antimicrobial properties of actinomycetes from the soil of Himalaya. J Mycol Méd 2010; 20(1): 15-20.

[37] Ramadan MF, Asker MMS, Ibrahim ZK. Functional bioactive compounds \& biological activities of Spirulina platensis lipids, Czech. J Food Sci 2008; 26: 211-22.

[38] Pandey B, Ghimire P, Agrawal VP. Studies on the antibacterial activity of the actinomycetes isolated from the Khumbu region of Nepal. Appl Microbiol 2008; 5: 235-61.

[39] Sudha SS, Karthik R, Francis M, Saumya TS, Ramanujan JR. Isolation and preliminary characterization of associated microorganisms from Spirulina products and their silver mediated nanoparticle synthesis. J Algal Biomass Util 2011; 2: 1-8.

[40] Hube AE, Soller BH, Fischer U. Phylogenetic classification of heterotrophic bacteria associated with filamentous marine cyanobacterial in culture. Syst Appl Microbiol 2009; 32: 256-65.

[41] Thajuddin N, Subramanian G. Cyanobacterial biodiversity \& potential applications in biotechnology. Curr Sci 2005; 89(1): 47-57.

[42] Hassan AA, El-Barawy AM, Mokhtar El, Nahed M. Evaluation of biological compounds of Streptomyces species for control of some fungal diseases. J Am Sci 2011; 7(4): 752-60.

[43] Youjiu T, Yi P, Yongchun H. Selective separation of actinomycetes from soils and rapid evaluation of antiphytopathogenic activity of their metabolities. Plant Prot 2011; 37(1): 120-3.

[44] Lalitha S, Gowthami DK, Kumar KS. In vivo screening of antimicrobial activity of soil Actinomycetes against human pathogens. World J Agric Sci 2011; 7(5): 624-8.

[45] Mukherjee P, Ahmad AS, Kumar R. Fungus mediated synthesis of silver nano particles and nanolett their immobilization in mycelia matrix. A novel biological approach to nanoparticle synthesis. Nano Lett 2001; 1: 515-19.

[46] Praveen KR, Vijayan D, Leo AM, Muthu KC, Thajuddin N Phylogenetic diversity of cultivable bacteria associated with filamentous non - heterocystous marine cyanobacteria. J Algal Biomass Util 2009; 1(1): 86-101.

[47] Andreote FD, Pietrobon VC, Andreote FD, et al. Genetic variability of Brazilian isolates of Alternaria alternate detected by AFLP and RAPD techniques. Braz J Microbiol 2009; 40: 670-7.

[48] Croft MT, Lawrence AD, Deery ER, et al. Algae acquire vitamin B12 through a symbiotic relationship with bacteria. Nature 2005; 483: 90-3.

[49] Bruno L, Billi D, Albertano P. Genetic characterization of epilithic cyanobacteria and their associated bacteria. Geomicrobiol J 2006; 23: 293-9.

[50] Jasti S, Sieracki ME, Poulton NJ, et al. Phylogenetic diversity and specificity of bacteria closely associated with Alexandrium spp. and other phytoplankton. Appl Environ Microbiol 2005; 71(2): 3483-94.

[51] Kolmonen E, Sivonen K, Rapala J, Haukka K. Diversity of cyanobacteria and heterotrophic bacteria in cyanobacterial blooms in Lake Joutikas, Finland. Aquat Microb Ecol 2004; 36: 201-11.

[52] Hempel M, Blume M, Blindow I, Gross EM. Epiphytic bacterial community composition on two common submerged macrophytes in brackish water and freshwater. BMC Microbiol 2008; 8(58): 1-10.

[53] Madaan N, Mudgal V, Mishra S, Srivastava AK, Singh RB. Studies on biochemical role of accumulation of heavy metals in safflower. Open Nutr J 2011; 4: 199-204.

[54] Ter Laak TL, Gebbink WA, Tolls J. The effect of $\mathrm{pH}$ and ionic strength on the sorption of sulfachloropyridazine, tylosin, and oxytetracycline to soil. Environ Toxicol Chem 2006; 25: 904-11. 
[55] Gao J, Pedersen JA. Adsorption of sulfonamide antimicrobial agents to clay minerals. Environ Sci Technol 2005; 39: 9509-16.

[56] Kurwadkar KT, Adams CD, Meyer MT, Kolpin DW. Effects of sorbate speciation on sorption of selected sulfonamides in three loamy soils. J Agric Food Chem 2007; 55: 1370-76.

[57] Thiele-Bruhn S, Seibicke T, Schulten HR, Leinweber P. Sorption of sulfonamide pharmaceutical antibiotics on whole soils and particle-size fractions. J Environ Qual 2004; 33: 1331-42.
[58] Gao J, Pedersen JA. Sorption of sulfonamide antimicrobial agents to humic acid-clay complexes. J Environ Qual 2009; 39: 228-35.

[59] Kahle M, Stamm C. Sorption of the veterinary antimicrobial sulfathiazole to organic materials of different origin. Environ Sci Technol 2007; 41: 132-8.

[60] Förster M, Laabs V, Lamshöft M, et al. Sequestration of manureapplied sulfadiazine residues in soils. Environ Sci Technol 2009; 43: $1824-30$.

Received: February 07, 2012

Revised: March 21, 2012

Accepted: March 26, 2012

(C) Singh et al.; Licensee Bentham Open.

This is an open access article licensed under the terms of the Creative Commons Attribution Non-Commercial License (http://creativecommons. org/licenses/ by-nc/3. 0/) which permits unrestricted, non-commercial use, distribution and reproduction in any medium, provided the work is properly cited. 